Pană D.P. ${ }^{1}$, Georgescu Carmen ${ }^{1}$, Mitran M. ${ }^{1}$, Mitran Loredana ${ }^{2}$

\title{
Postpartum Hemorrhage after Cesarean Delivery - Causes and Management Statistics of "Prof. Dr. Panait Sîrbu "Hosnital- Bucharest
}

'The Clinical Hospital of Obstetrics and Gynecology "Prof. Dr. Panait Sîrbu ", Bucharest ${ }^{2}$, „Elias” Emergency Hospital Bucharest

\begin{abstract}
Postpartum hemorrhages represent a major cause of maternal mortality everywhere in the world and in Romania obstetrical hemorrhages are directly incriminated in $47.85 \%$ from the cases reported between $1975-2010$. This retrospective study over a period of five years (2008 - 2012) includes the clinical-statistical analysis of postpartum hemorrhages (PPH) registered in "Prof. Dr. Panait Sîrbu" Clinical Hospital of Obstetrics and Gynecology in Bucharest. During the period under analysis there were 20204 births, out of which 13012 were vaginal and 7192 by caesarean section. There were 853 cases of postpartum hemorrhage with significant clinical manifestations, which required medical management, $4.22 \%$ of all births. In 459 cases there were reported hemorrhagic complications after caesarean section $(6.368 \%$ of caesarean sections), representing $53.81 \%$ of postpartum hemorrhage. The severity of intra-operative and post-cesarean bleeding is due to its association to anesthetic risk, which is more important in cesarean, as well as to the associated pathology that indicated the caesarean section in the first place.

Keywords: postpartum hemorrhage, cesarean section, delivery
\end{abstract}

Dr. Doru Pană

e-mail:dorupana@yahoo.com

\section{Introduction}

Postpartum hemorrhages represent a major cause of maternal mortality everywhere in the world and in Romania obstetrical hemorrhages are directly incriminated in $47.85 \%$ from the cases reported between $1975-2010[1,2]$.

\section{Methods}

This retrospective study over a period of five years (2008-2012) includes the clinical-statistical analysis of postpartum hemorrhages (PPH) registered in "Prof. Dr. Panait Sîrbu" Clinical Hospital of Obstetrics and Gynecology in Bucharest. During the period under analysis there were 20204 births, out of which 13012 were vaginal and 7192 by caesarean section. 


\section{Results}

There were 853 cases of postpartum hemorrhage with significant clinical manifestations, which required medical treatment and hemostasis measures (representing $4.22 \%$ of all births) compared to Jacobs (10\%) and acc. to WHO 2000 Report $(10.5 \%)$ [2].

In 459 cases there were reported hemorrhagic complications after caesarean section (6.368\% of caesarean sections), representing $53.81 \%$ of postpartum hemorrhage.

Specific for bleeding after caesarean section is:

- The severity of the bleeding - normal blood loss after cesarean birth is higher than after natural birth -

- Bleeding added to the pathology that indicated caesarean section

- Favoring uterine atony due to lack of contraction of the myometrium during the refractory period $[3,4,5,6,7,8]$

Intra and post caesarean section hemorrhage was caused by:

- $\quad$ Primary uterine atony: 277 cases

- Placental abruption: 94 cases

- Defects in placental insertion: 67 cases,

- Uterine rupture: 4 cases (2 after cesarean section, 1 post-myomectomy, 1 during labor on apparently unscarred uterus)

- $\quad$ Persistent late hemorrhage: 17 cases

We included in the study only cases of heavy bleeding which required intensive care measures, with severe secondary anemia (hemoglobin $<8.5 \mathrm{~g} / \mathrm{dL}, \mathrm{Ht}$ $<19$ ), which resulted in coagulation disorders in all cases (67 of which with preeclampsia). Intraoperative, uterus was pale, mottled with petechiae, without contractility.

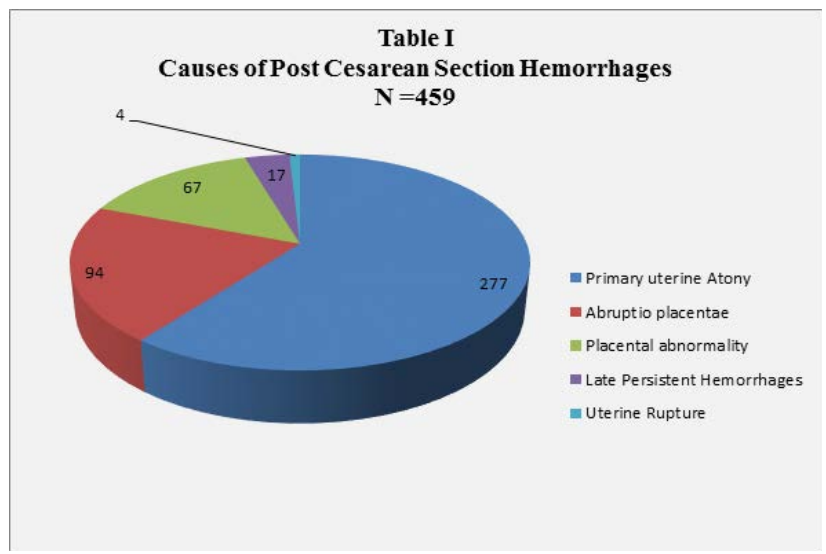

PRIMARY UTERINE ATONY: 277 cases represented $60.35 \%$ of post- cesarean bleeding. Possible causes of the emergence of atony are highlighted in the chart below:

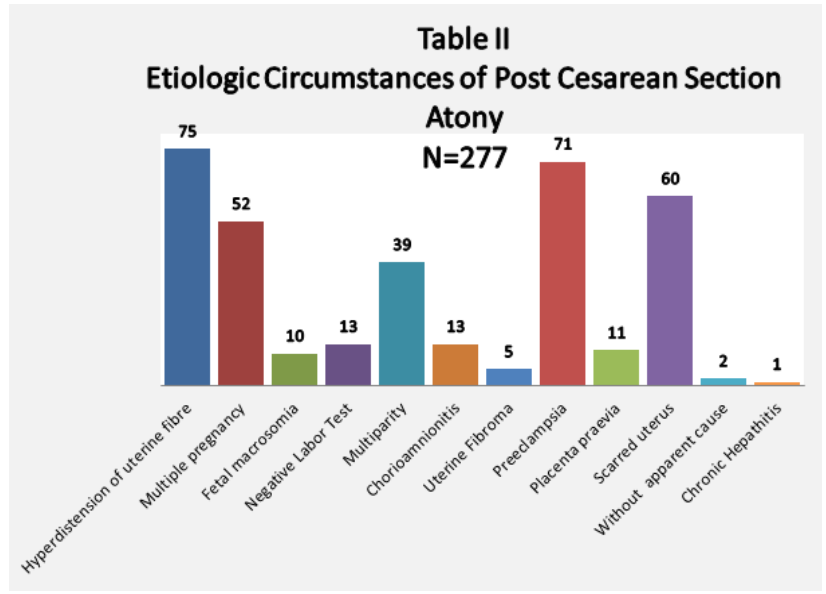

In accordance with the literature [5,9], we assumed that chronic anemia preexistent to caesarean section was a contributing, aggravating factor in 194 cases $(70 \%)$ who had $\mathrm{Hb}<10 \mathrm{~g} / \mathrm{dL}$ with normocytosis (106 cases) or microcytosis (86 cases), hypochromia in all cases; 2 cases with preeclampsia, diabetes mellitus and hypothyroidism presented macrocytic anemia. Serum iron values were below $55 \mu \mathrm{g} / \mathrm{dL}$. The atony mechanism would be represented by $\mathrm{Fe}$ deficiency interfering through cytochrome oxidase with the mechanism of myometrium contraction.

SURGICAL TREATMENT OF POST CESAREAN HEMORRHAGE

Of the 459 cases of hemorrhage after cesarean 
section, 181 required treatment for hemostasis $(39.43 \%)$.

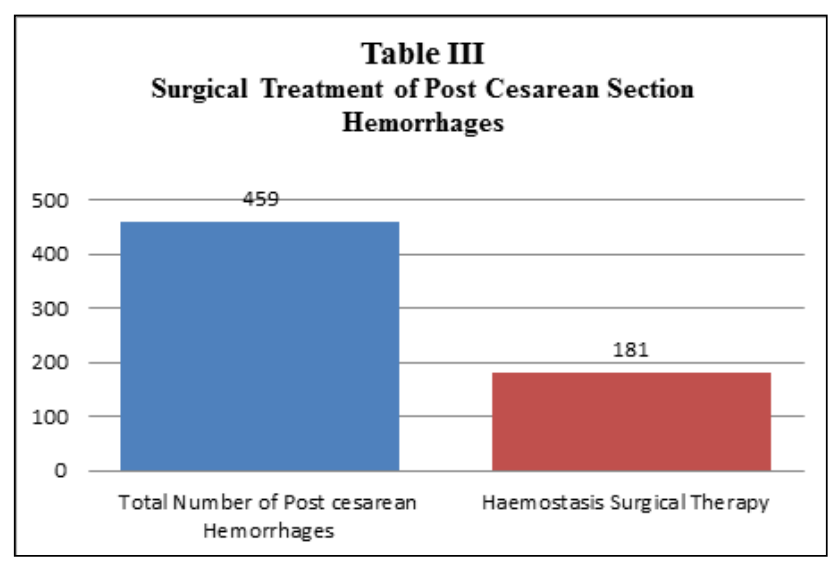

Following cesarean section, 116 total hysterectomies were performed and one subtotal hemostatic hysterectomy, in the following situations:

- Uteroplacental Apoplexy: 61 cases plus 2 cases where uteroplacental apoplexy was also associated with dead fetus and a scarred uterus.

- Pathological Placenta: 19 cases, namely: in 11 cases placenta praevia, in 5 cases placenta accreta and in 3 cases placenta percreta

- Uterine atony in 30 cases: 10 cases preeclampsia, uterine scar 17 cases, 1 case twin pregnancy (subtotal hysterectomy), underlying disease: chronic hepatitis: 1 case; 1 case of HIV infection.

- Uterine Rupture: 4 cases

- Isthmic Uterine Fibroids: 1 case

Immediate reoperation with total hysterectomy was performed in 45 cases:

- Uteroplacental Apoplexy 16 cases

- Pathological placenta (praevia) 8 cases.

Late reoperation was performed in 2 cases with total hysterectomy for placenta accreta.

In 17 cases with late hemorrhage after cesarean section per hysteroscopy hemostasis was performed thus:

- hemostasis by electrocoagulation of bleeding sites in 7 cases

- extracting the remaining wires from the tranche of hysterotomy and electrocoagulation of bleeding sites in 10 cases. In these patients, on a background of continuous bleeding without fluctuations, the bleeding became abundant on days 24-36 after birth by caesarean section, which required hemostasis. All patients presented secondary anemia with $\mathrm{Hb}=7-9 \mathrm{~g} /$ $\mathrm{dL}$, without any coagulation disorders.

In all cases of early reintervention, consumption and dilutional coagulopathy was present with: Platelets $<80000 / \mathrm{MMC}$ (in 3 cases $=20-30.000 /$ $\mathrm{mmc}$ ), fibrinogen $<1 \mathrm{~g} / \mathrm{dl}$, the presence of fibrin degradation product (FDP) in all cases, and D-dimers in 9 cases, with altered coagulogram in all the 79 cases requiring hemostatic hysterectomy. Hematological rebalancing was made by administering fresh blood, FFP, platelet mass, cryoprecipitate, antifibrinolytic (6 cases). Preservation of the uterus was obtained in only 15 cases $(15.95 \%)$; in all of them uterine artery ligation was performed [10]. Continuous vertical compression over the uterine vessels was done by B-Lynch compression suture $[3,10,11]$ where there was abundant bleeding during caesarean section, after exhausting other conservative methods before the decision for hemostatic hysterectomy in 8 cases. Bleeding occurred in: primary atony 1 case, atony by fiber hyperdistension in 3 cases (twin pregnancy in 2 cases, negative labor test 1 case), lack of retraction of the lower segment by praevia insertion of placenta 1 case and uterine scar 3 cases. The result was good in 6 cases. The Clinic staff had positive results when distance assessing the endometrium post B-Lynch compression suture by hysteroscopy and endometrial biopsy.

Uterine artery ligation was performed in 178 cases:

- 73 cases before the decision for hysterectomy intraoperative: 16 with primary atony 10 with preeclampsia, 16 with scarred uterus, 19 placenta praevia, 12 with uteroplacental apoplexy.

- in 30 cases, uterine artery ligation did not achieve hemostasis, therefore reintervention was necessary immediately after caesarean section to ensure hemostasis: 6 with preeclampsia, 16 with scarred uterus and 8 with placenta praevia.

- in 75 cases conservative treatment was effective.

Haemostasis in the placental bed was done in 60 cases 


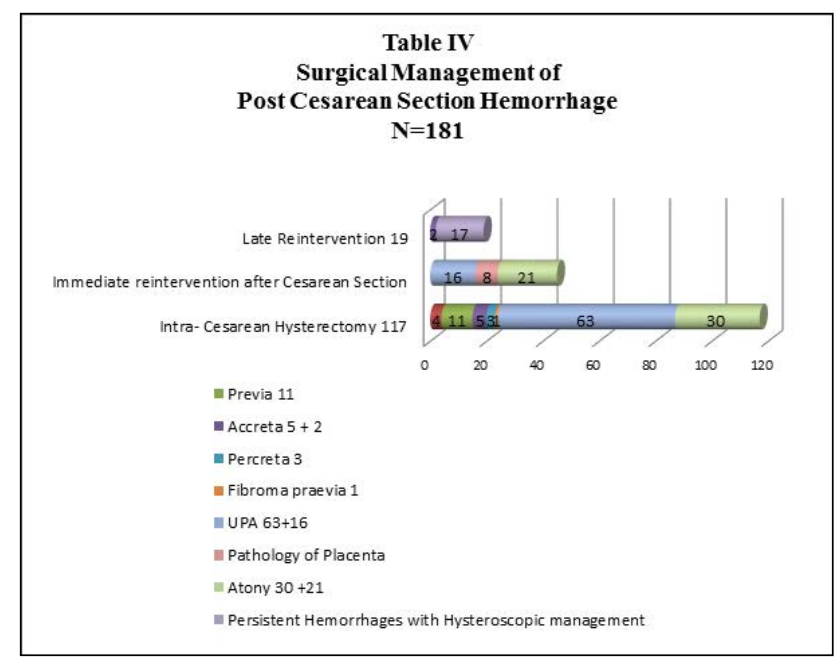

Conclusions

The severity of intra-operative and postcesarean bleeding is due to its association to anesthetic risk, which is more important in cesarean, as well as to the associated pathology that indicated the caesarean section in the first place. What stands out is uteroplacental apoplexy (94 cases), abnormal placentation (67 cases), preeclampsia (71 cases).

Parity was irrelevant for the study, probably due to the low percentage of registered multiparous (2.85\% of all births).

What is significant for the occurrence, and especially for the severity of bleeding complications, is the association of pregnancy pathology with a potential for coagulopathy.

Myometrial fiber hyperdistension was determinant or adjuvant for the occurrence of the bleeding accident in 75 cases of bleeding after caesarean section.

Uterine atony is the most important cause of postpartum hemorrhage $[4,6,7,9]$ reported in 394 cases $(46.18 \%)$. It has a lower occurrence after vaginal birth (117 cases $-29.7 \%$ ) than after caesarean section ( 277 cases $-60.35 \%$ ). In $42.64 \%$ of the cases, atony led to hysterectomy for hemostasis [12] (168 cases), 6 cases after spontaneous birth (5.13\%) and
162 cases after cesarean section (58.48\%).

Conservative treatment was the first intention in all cases. Before the decision for hysterectomy, conservative treatment was attempted by uterine artery ligation, in situ hemostasis or using B-Lynch vascular sutures $[3,10,11,13,14,15]$. Uterine artery ligation, done in 178 of the cases, facilitated uterine conservation in 75 cases (42\%). B-Lynch suture $[3,10]$, performed in 8 cases, led to the conservation of the uterus in 7 cases.

In 3 cases, the association of pathology likely to induce coagulation disorders, namely systemic lupus, chronic hepatitis, HIV infection stage 3 or 4, which determined hemorrhage with coagulation disorders, imposed radical surgery- total hysterectomy- as a measure to prevent the aggravation of the coagulation disorders.

It is recommended that conservative methods of treatment should be attempted [15]: uterine artery ligation [10], B-Lynch suture [3,11], hypogastric artery ligation [13], before the radical decision for hemostatic hysterectomy, as a large number of cases (42-45\% in our study) can be resolved conservatively.

\section{References}

1. Suciu N., Nicolescu S., Bănceanu G., Marinescu B. \& Szabo B. (2011). Mortalitatea maternă în România: 2006-2010. IOMC, Soc de ObstGinecol din Romania

2. World Health Organization. (2005). The World Report 2005. Attending to 136 million births, every year; 2005. Make every mother and child count. Geneva, The World Health Organization, 61-63

3. B-Lynch C., Coker A., Lawal A.H., Abu J. \& Cowen M J. (1997). The B-Lynch surgical technique for the control of massive postpartum hemorrhage: an alternative to hysterectomy. $\mathrm{Br}$. J. Obst. Gynecol. 104(3), 372-375

4. B-Lynch C., Keith L.G. \& Lalonde A.B. (2006). A textbook of Postpartum Hemorrhage; a 
comprehensive guide to evaluation, management and surgical intervention. Sapients Publishing

5. Luca V. (1994). Hemoragiile obstetricale. Bucuresti: Ed Cerna

6. Mousa H.A. \& Walkin Shaw S. (2001). Major postpartum Hemorrhage. Obst. Gynecol. 13, 595-596

7. Pahlavan P. \& Nezhat C. (2001). Hemorrhage in obstetric and gynecology. Obst Gynecol. 13, 419-420

8. Pană P.D., Georgescu C. \& Mitran M. (2013). Postpartum Hemorrhages. Gineco.Eu. 9(31), 1925

9. Pelinescu-Onciul D. (2005). Hemoragiile obstetricale. Etiologie. Fiziopatologie. Obst. Ginec. LIII, 17-24

10. Hayman R.G., Arulkumaran S. \& Steer P.J. (2002). Uterine compression suture; surgical management of postpartum hemorrhage. Obst. Gynecol. 99(3), 502-506
11. Ion I., Enache T., Drâmbărean D., Vultur A., Tașcă L. \& Pană P.D. (2010). Sutura compresivă B-Lynch. Metodă conservativă de tratament a atoniei uterine. Obst Ginec. LVIII, 213-218

12. Luca V. \& Nanu D. (1987). Histerectomia de necesitate în puerperalitate. Obst Ginec. 2, 149150

13. Clark S.L., Phelan J.P., Yeh S.Y., Bruce S.R. \& Paul R.H. (1985). Hypogastric artery ligation for obstetric hemorrhage. Obst. Gynecol. 66(3), 353356

14. Sergent F. \& Resch B. (2005). Hemorragies graves de la delivrance: ligatures vasculaires, hysterectomie ou embolisation? EMC GynecolObstetrique. 2 125-136

15. Suciu N., Bănceanu G., Oprescu D. \& Pechi L. (2010). Non surgical treatment in postpartum hemorrhage over hemostatic hysterectomy. $J$ Mat-Fetal\&Neonat Med. 23, 72 